\title{
HUMILIS STYLUS. CREATIVIDAD Y NARRACIÓN LITERARIA EN LA OBRA DE CARMELO LISÓN
}

\author{
Humilis Stylus. Creativity and Literary Narration \\ in the Work of Carmelo Lisón
}

\section{Humilis Stylus. Criatividade e narração literária na obra de Carmelo Lisón}

\author{
Carlos MONTEs PÉREZ \\ Universidad de Salamanca \\ cmontes@usal.es
}

Fecha de recepción: 26/04/2021

Fecha de aceptación: 3/05/2021

RESUMEN: En la obra del profesor Lisón la presencia de la literatura resulta habitual. En muchos de sus escritos establece diálogos con sus autores de referencia para ofrecer al lector una perspectiva antropológica de la imaginación literaria. En este trabajo exponemos algunas de las reflexiones del antropólogo aragonés sobre la creatividad y la cultura y sobre la literatura, para centrarnos en el análisis cultural que lleva a cabo sobre El Quijote de Cervantes.

Palabras clave: creatividad; literatura etnográfica; Carmelo Lisón; El Quijote.

ABSTRACT: In the work of Professor Lisón the presence of literature is very common. In many of his writings he establishes dialogues with his reference authors to offer the reader an anthropological perspective of the literary imagination. In this work we present some of the reflections of the Aragonese anthropologist on creativity and culture, on literature, to focus on the cultural analysis that he carries out on Cervantes's Don Quixote. 
Key word: Creativity; Ethnographic literature; Carmelo Lisón; El Quijote.

RESUMO: Na obra do professor Lisón, é habitual a presença da literatura. Em muitos de seus escritos estabelece diálogos com seus autores de referência para oferecer ao leitor uma perspectiva antropológica da imaginação literária. Neste trabalho expomos algumas das reflexões do antropólogo aragonês sobre a criatividade e a cultura e sobre a literatura, para centrar-nos na análise cultura que leva a cabo sobre Don Quixote de Cervantes.

Palavras-chave: Criatividade; literatura etnográfica; Carmelo Lisón; Don Quijote.

\section{INTRODUCCIÓN}

Muy pronto me fascinó la historia de la literatura española del profesor Blecua por su estilo, variedad de escritores y selección de argumentos narrativos sobre la vida y la belleza, lo que me espoleó para ensanchar con avidez el arco bibliográfico según mis posibilidades; con el tiempo inclui obras de historia, arte, literatura -los gigantes clásicos del pensamiento y de la imaginación-, filosofía y antropología. Quiero recordar que la humanidad toda se ha regido y en parte se rige por un conjunto de libros que sirven de paradigmas para el cultivo del espiritu en sabiduría, convivencia y solidaridad. Los diez mil libros de mi biblioteca donados al municipio son una invitación a la lectura reposada y pensativa a mis vecinos porque el conocimiento es una de las joyas personales que más enriquecen al individuo. Más aun, la sabiduría, la cultura, la creatividad imaginativa del espiritu y su absorción es lo que nos hace realmente humanos, lo que nos distingue en el cosmos que habitamos.

(Palabras del profesor Lisón. Fundación Lisón Donald).

En el discurso pronunciado por el profesor Carmelo Lisón en el Acto de investidura como Doctor Honoris Causa por la Universidad de Murcia, allá por el año 2011, expresaba su incondicional deseo de seguir activo a pesar ya de su edad afirmando que seguiría en la labor docente "mientras dure el aceite de mi lámpara ${ }^{1}$. Desafortunadamente el aceite de su lámpara vital se extinguió hace algunos meses. En este tiempo, a los antropólogos que tuvimos el privilegio de contar con su magisterio, nos ha invadido un profundo sentimiento de orfandad intelectual y una cierta melancolía. Aún recuerdo vivamente cómo muchos de los estudiantes de principios de los años noventa esperábamos con curiosidad los programas de la Universidad Internacional Menéndez Pelayo donde nos

1. Publicado en Discursos pronunciados en el Acto de Investidura del profesor D. Carmelo Lisón Tolosana como Doctor Honoris Causa por la Universidad de Murcia. Murcia, 2011. 
encontrábamos, año tras año, con el profesor Lisón junto con un nutrido grupo de profesores que, bajo su amistad y coordinación contribuyeron a dotar de visibilidad a la disciplina antropológica en un país donde su presencia era aún muy escasa, y donde la opinión pública, en general, desconocía el verdadero oficio de la etnografía, así como su proyección social y cultural.

En muchos de nosotros, procedentes inicialmente de disciplinas diversas, filología y filosofía en nuestro caso, el oído atento al siempre sugerente discurso del profesor Lisón, las prácticas de campo que acompañaban al curso, las lecturas reposadas al lado del mar de los textos propuestos, y los paseos y comidas en grupo entre alumnos y profesores nos inclinaron definitivamente hacia el interés por la cultura y sus casi infinitas prácticas y manifestaciones. Este nutrido y variado grupo de profesores de estos cursos de verano se han convertido con el tiempo en referencia nacional e internacional en las ciencias sociales y, han destacando sobre todo por sus contribuciones a la antropología. Un buen número de estudiantes que en su momento pasamos por las aulas de las caballerizas cántabras hemos convertido a esta disciplina académica, en sus distintas especialidades, en nuestra labor diaria, tarea profesional y en nuestra pasión intelectual.

Consideramos que no se ha valorado suficientemente la influencia que estos cursos de verano, promovidos y dirigidos por el profesor Lisón, ha tenido en el desarrollo de la intrahistoria de la antropología española. No es la primera vez que, en algún congreso o encuentro especializado, y en medio de una conversación informal, sale a colación la presencia conjunta en dichos cursos: la mera mención de "yo también estuve allì" crea vínculos afectivos y de cercanía. Era la primera vez que en nuestro país se llevaba a cabo una formación de este tipo. Resultaba novedoso en la academia española de mediados de los noventa un modelo de curso que tuviera además de la parte expositiva y magistral, una parte práctica, etnográfica, que consistía en un trabajo de campo financiado y que debía realizarse en un intervalo de tiempo prudencial, dirigido por profesores del curso y que era preceptivo someterlo después a exposición ante un pequeño tribunal de profesores del curso. Así, de esta manera, pude acercarme a las costumbres cántabras en mi primer acercamiento al trabajo de campo, y al análisis antropológico de los espacios públicos, en concreto de la plaza mayor de Salamanca en mi segunda estancia en la Universidad Internacional Menéndez Pelayo. Aún recuerdo el acertado juicio y las palabras de ánimo del profesor Lisón en la exposición de mis primeras impresiones sobre el trabajo de campo, los acertados y sabios comentarios del profesor Gómez Pellón sobre mi breve etnografía cántabra, y los generosos elogios del siempre apasionado antropólogo Gaspar Mairal sobre la etnografía urbana de los espacios públicos.

Aparte de estos recuerdos y vivencias personales en momentos pasados de nuestra formación académica, afortunadamente nos ha legado un conjunto extenso de textos, referencias, conferencias y escritos de géneros distintos aún por escudriñar y valorar en su justa medida. Hemos admirado de forma recurrente el vasto conocimiento de disciplinas que desde la neurología hasta la filosofía enriquecen 
enormemente los textos e investigaciones del profesor aragonés. Hemos sentido una curiosidad y fascinación especial por su modo personal de hacer etnografía, una de sus grandes virtudes, y por su particularísimo modo escrito de presentarla, otro de sus grandes talentos, como bien ha sido descrito ya en contadas ocasiones. (San Martín, 2020: 105).

La antropología, como disciplina académica en nuestro país, no puede pensarse sin la aportación del profesor Lisón. Sus reflexiones sobre metodología, etnografía, simbolismo, cultura popular, etcétera, merecen la consideración de aportaciones clásicas. Ahora bien, junto a todo esto, es de justicia reconocer también cómo la curiosidad intelectual le ha empujado a acercarse con cautela a disciplinas distintas a la antropología con una clara convicción de interdisciplinaridad y con una cautela que él mismo describe como bumilis stylus. Hay numerosas referencias en su obra a la necesidad de complementar el conocimiento etnográfico acudiendo a otros saberes, pues el carácter poliédrico de la experiencia humana obliga a situarnos en perspectivas epistemológicas variadas. Junto a esto, también supo ofrecer perspectivas antropológicas en parcelas de la realidad que habían estado alejadas tradicionalmente de esta mirada como el arte, la creación pictórica o la literatura.

Como habitamos una casa con muchas mansiones precisamos, además, de un método poliédrico y promiscuo, multiplicar los puntos de vista y aprovechar el botín que traemos a las razzias a disciplinas afines como la Historia, la Geografía humana, la Semiología y la Crítica literaria. Como Rimbaud interpretamos litteralment et dans tous les sens (Lisón, 1998, 20).

Presencia de variadas disciplinas que se acompañan con frecuencia de citas y alusiones procedentes de tradiciones culturales distintas a la hispánica. Aparecen en sus escritos en la lengua original para apostillar un pensamiento, justificarlo, reforzarlo o para abrir nuevos espacios a la reflexión. Buen conocedor de la historia de la filosofía occidental, salpica sus trabajos con certeras alusiones a términos ingleses y alemanes, cuando no ofrece sabias referencias clásicas, en una clara búsqueda de precisión expresiva, con un objetivo casi fenomenológico de acudir a los términos mismos. Es consciente, por tanto, de que la antropología está necesitada siempre de fieles compañeros y compañeras de camino, disciplinas que aún partiendo de principios distintos y con metodologías diversas abrazan y complementan el pensamiento antropológico. Filosofía, Historia, Arqueología, Geografía y Literatura son algunas de estas compañeras de viaje que discretamente aparecen en sus escritos.

En todo caso entre mis postulados antropológicos figura siempre como inicial tarea exorcizar tanto los idola fori como la ignoratio elenchi (Lison, 1996, 32).

Esta búsqueda de la precisión conceptual y el apoyo de otras disciplinas tiene un claro propósito, que se convierte casi en una obsesión académica, al viejo estilo baconiano: vaciar nuestra mente de estos falsos conocimientos o errores 
que enturbian en pensamiento. Los ídolos del foro, o los producidos en corrillos de mercados refieren erróneamente a realidades que no existen, o que son definidas de manera inadecuada o usados de forma confusa. Sabemos que Francis Bacon dedicó un esfuerzo especial para refinar el debate, la investigación y el conocimiento de estos falsos saberes. Es el profesor Lisón un digno sucesor de este programa moderno, asumió su papel de intelectual comprometido con evitar las conclusiones irrelevantes y las semejanzas semánticas superficiales. Es, como él mismo señala, su postulado antropológico. La labor en determinadas ocasiones se vuelve hercúlea, los ídolos baconianos presionan por todos los rincones y aparecen con inusitada fuerza simplificando una realidad humana ya de por si compleja. Por tanto, la antropología del profesor Lisón apela a la realidad misma, al objeto y la práctica dotada de propiedades que no poseen per se, sino que se conforman antropológicamente, culturalmente.

La virgen del Pilar no es un mero bloque de mármol. Narcotizamos éste para establecer nuestra mansión investigadora en la reflexión sobre las propiedades representacionales, cualidades expresivas y funciones simbólicas. ¿qué quieren decir estas? ¿qué mensajes envían?¿qué cuenta como representación de qué?̨icómo representamos? Este enfoque implica que nuestras realidades físicas son esencialmente elaboraciones del espíritu, construcciones mentales, significado y valor, en una palabra (Lisón, 1996, 35).

Su antropología es marcadamente empirista, fáctica en su punto de partida y en sus fases más germinales, pero no así en el momento conclusivo. Desde un punto de vista general, el profesor Lisón insiste reiteradamente en apelar a los hechos, la realidad percibida, sentida y observada es el único punto de partida para el análisis cultural. Por este motivo, como veremos, hay en la construcción de su pensamiento antropológico una llamada constante al empirismo clásico inglés combinado por las ideas más germánicas que tienen como partida esa «vuelta a las cosas mismas» y que él mismo describe como fenomenología existencial.

Nos movemos en el área de nuestra fenomenología existencial, en el primado de las Seinsfrage y de la historicidad que vehicula conceptos de valor, de intención y pasión y semánticas de sentido y significado»2 (Lison, 2013, 7).

En realidad se unen en este punto de partida las dos grandes tradiciones culturales en las que el profesor Lisón se formó, la tradición británica, más asentada sobre lo fáctico, y la tradición alemana, que propone la interpretación de los hechos a través del ejercicio hermeneútico del verstehen que aplica con maestría a las que él denomina como las Seinsfrage, las preguntas antropológicas clave, las

2. Es una nota característica de su estilo de narrador el introducir conceptos en su idioma original. La presencia de palabras en alemán en sus escritos es muy numerosa. El profesor Lisón era un gran conocedor de la cultura filosófica alemana. 
dovelas de la existencia humana que veremos cómo no aparecen solamente en la vida cotidiana que observamos en el trabajo de campo, sino que han sido recogidas también por los grandes escritores clásicos.

Son las llamadas Seinsfrage, aquellas que versan sobre significados y fines últimos, sobre el Bien y el Mal, sobre el poder y la jerarquía; preguntas que cuestionan el traumatizante dolor, la injusticia y la muerte, preguntas que buscan fundamentar la moral personal, la ética ciudadana y el valor social. Preguntas todas ellas imprecisas, loco-tempo sensibles, ambiguas porque todas se refieren a nociones sománticamente indeterminadas. Pero imprescindibles en nuestra investigación final (Lison, 1996, 36).

Este mundo de los hechos es la materia de la que se nutre el pensamiento etnográfico, elemento claramente distintivo y diferenciador de otros conocimientos humanos. No hay otra puerta de entrada a la experiencia humana más que lo fáctico. La insistencia del profesor aragonés en este asunto es uno de los rasgos definitorios de su metodología antropológica, pues los hechos, cuando son humanos, es decir, cuando son producto de la sociabilidad humana, van más allá de lo puramente percibido, son más que hechos mismos, florecen y florecen en significados necesitados de interpretación.

La metáfora del propio Lisón es enormemente rica pues pone de manifiesto cómo estos significados producidos localmente son accesibles de modo intercultural, lo que hace posible la antropología como ciencia. Ahora bien, es necesario recordar que no se trata de una ciencia cualquiera que se ocupa de un fragmento de la realidad. En este caso es una ciencia específica y holística en su modo de tratar a su objeto más valioso, el ser humano. Una disciplina que lejos de la exactitud e infalibilidad, se encuentra más cómoda en el claro oscuro, en la perplejidad, a veces en la ambigüedad, y en muchas ocasiones en la aporía; una disciplina que se apoya en el conocimiento y la experiencia de otras ciencias humanas y sociales y que se ocupa, de forma directa con las misteriosas y maravillosas formas de la creatividad humana. Por todo ello, y siguiendo la propia naturaleza de su objeto de análisis, el pensamiento del profesor Lisón desborda la temática más clásica antropológica y se adentra en otras formas de epistemologías como la Crítica literaria, de la que nos ocuparemos brevemente en las líneas siguientes. Ahora bien, utilizando sus propias palabras, en todo aquello que complementa a la antropología, su acercamiento es siempre prudente, lo lleva a cabo bajo bumilis stylus.

\section{Humilis stYlus. TONO MENOR}

La reflexión sobre el estilo de la palabra y su relación con la realidad que se describe y refiere ya fue motivo de elaboración y reflexión desde el mundo clásico. De esto bien sabe el profesor Lisón. Aristóteles en su conocida Ética a Nicómaco diferencia los distintos caracteres personales por la elocución propia. 
Dime cómo te expresas y te diré en carácter que posees. El estagirita diferencia entre bufones y vulgares, rudos y ásperos, e ingeniosos y ágiles de mente.

(...) los que se exceden en provocar la risa son considerados bufones o vulgares, pues procuran por todos los medios hacer reír y tienden más a provocar la risa que a decir cosas agradables o a no molestar al que es objeto de sus burlas. Por el contrario, los que no dicen nada que pueda provocar la risa y se molestan contra los que lo consiguen, parecen rudos y ásperos. A los que divierten a los otros decorosamente se les llama ingeniosos, es decir, ágiles de mente, pues tales movimientos se consideran notas de carácter, y lo mismo que juzgamos a los cuerpos por sus movimientos, lo hacemos también con el carácter (Arist. Ét. Nic. IV, 8).

Tenemos en la referencia del filósofo macedónico un germen de los tratados posteriores sobre estos tres estilos. Algunos teóricos parten de él, como es el caso de Teofrastro, y otros muchos que escribieron tratados sobre la relación entre el modo de relatar y el modo de ser a lo largo del tiempo. Esta acomodación continúa en los tratados clásicos y medievales de retórica y parecen continuar hasta la obra del profesor Lisón, pues su estilo bien parece una nota de carácter como refiere el estagirita. Ingenioso y ágil de mente, irónico en algunos pasajes, profundo y preciso en sus expresiones, cuidado en el estilo y, sobre todo, dotado de una habilidad destacada para la escucha y la categorización de lo ajeno. En gran medida curioso y con un afán desmedido por conocer otras perspectivas de lo humano más allá de la mirada antropológica, pero siempre con prudencia y cautela, como bien resume la expresión bumilis stylus.

\section{CReatividad}

La obra de Carmelo Lisón transita en múltiples ocasiones por espacios ajenos al canon establecido, se abre a temáticas inusuales que sorprenden y desconciertan al lector, pero se presenta, a su vez, llena de sugerencias y matices. En un breve texto publicado en Fundamentos de antropología aborda con precaución y bajo bumilis stylus la topografía cultural de la creatividad humana, la idea, el concepto y su relación con las prácticas culturales y, por añadidura, en una extensión de su interés por la imaginación cultural, se acerca a la literatura y al arte, espacios del modo de ser humano poco frecuentados por los antropólogos, con algunas valiosas excepciones como el caso del profesor Sanmartín, (Lisón, 1998: 183), el conocido trabajo de Manuel de la Fuente Lombo (Fuente Lombo, 1994: 6) o la dilatada atención prestada a esta temática por el profesor Luis Díaz Viana (Díaz Viana, 2005: 7-41).

Pensar la creatividad humana ha sido objeto de la psicología como función cognitiva, ahora bien, el tratamiento de esta capacidad humana, como el propio profesor aragonés describe, se trata de un difícil matrimonio entre un novio eminentemente cerebral y una novia con el máximo logaritmo de emotividad. En todo caso, parece que nada nos empuja hacia la antropología, sin embargo, es 
aquí donde radica el golpe de efecto. El estudio de la creatividad, nuestro acercamiento a su consideración como capacidad humana nos fuerza a enfrentarnos directamente con el núcleo de nuestra disciplina. No debe de ser algo marginal a la antropología, así lo siente el profesor Lisón, es más, al acercarnos al estudio de la creatividad, nos enfrentarnos con lo más radicalmente humano, con la cultura.

Efectivamente, creatividad forma un síndrome con estados mentales, conciencia, intención y significado, lo que quiere decir que para su análisis tenemos necesariamente que abordar conceptos culturales cruciales como experiencia perceptual, pensamientos, deseos, creencias, sensaciones, emociones, sentimientos, fabricaciones teórico-simbólicas, etc. es decir, lo más radicalmente humano y por lo tanto, lo fundamentalmente antropológico (Lisón, 2013, 233).

La cultura transita, se produce en esos espacios de creatividad individual y colectiva que se desparraman como un abanico en prácticas múltiples y variadas. Fiestas, rituales, mitologías, manifestaciones folclóricas, etc. pero también en metáforas literarias o en lienzos pictóricos. Los espacios humanos de la creatividad son múltiples; fruto de innovaciones geniales individuales, pero también como producto de innovaciones provocadas por una dinámica colectiva, tal y como han puesto de manifiesto expertos como Tapscottot y Willians (2006) y Sunstein (2006) y que pueden ser, por tanto, objeto máximo de interés antropológico bajo determinadas condiciones.

Novela, drama, poesía y épica, poetas desconocidos y pintores locales incluídos, son producciones del espíritu que no deben escapar a la consideración antropológica siempre que despojemos a todo este conjunto de creatividad hispana del velo de la supuesta familiaridad que lo cubre y le devolvamos la extrañeza de nuestra mirada antropológica (Lisón, 1996, 50).

Los momentos liminares y las condiciones primordiales de la existencia humana, unido, todo ello, a nuestra capacidad consciente han sido los motores de una explosión de creatividad humana en sus múltiples objetivaciones míticas, literarias, artísticas, metafísicas o incluso teológicas. El profesor Lisón, a lo largo de su dilatada y fecunda vida académica, sintió como su perspicaz atención por los asuntos humanos migraba sin cesar posándose en distintos aspectos que requerían sosiego. Así ocurrió con el asunto del mal, ejemplo de cómo estos estados de ánimo provocados por el lado oscuro de la existencia humana generan un impulso creativo que ha afectado a pensadores diversos a lo largo de la historia. La creatividad cultural bebe incesantemente de las fuentes del sufrimiento, de la desgracia humana, del dolor, de la enfermedad, de la mente e incluso de la locura, como veremos más adelante. Es precisamente en el análisis cultural del mal donde la obra de Lisón se adentra en territorios interdisciplinares. El pensamiento filosófico y la literatura van de la mano de la antropología en este hervor creativo. Figuras como Platón, Plotino, San Agustín, Santo Tomás, Filón de Alejandría abordan creativamente este trasunto humano que no es ajeno a literatos como Poe, Dante, 
Rousseau, Rimbaud, Valery, Milton, Dostoievski, Camus, Tomas Mann, y un sinfín de creadores por los cuales la obra del profesor Lisón ha transitado.

Lo insondable es para el arte, la literatura y la reflexión moral, no para la ciencia (Lisón, 2004).

Pero no se limita en su análisis de la creatividad humana a lo que él mismo llama la literatura de segundo nivel producida por los grandes literatos, sino que este no es más que un punto de llegada desde su partida inicial en el estudio de la creatividad humana en el corpus imaginario gallego, en lo que él mismo denomina como el primer nivel, el nivel local, un ámbito donde predominan las formas populares. Son numerosas las obras del profesor aragonés que han tomado con el tiempo ya la condición de clásicos, entre ellas se encuentran dos importantes escritos que, bajo el título de Demonios y exorcismos en el siglo de oro, abordan la creatividad humana y la vida mental referida al tema del mal, tal y como acertadamente se expone en el subtítulo. Los dos volúmenes pertenecen a la obra grande del antropólogo aragonés, y solamente, la presencia un tanto marginal de la antropología española en comparación con otras tradiciones más asentadas ha evitado que se sitúen entre los clásicos del pensamiento antropológico. En estos textos, fruto de un meritorio y dilatado trabajo de campo, se pone de manifiesto este carácter jánico de la existencia humana, donde lo insondable, el mal, el sufrimiento, la enfermedad no se deja atrapar por la racionalidad moderna que unifica el pensamiento y le confiere un patrón científico y cientificista, que se ve ampliamente desbordado por la creatividad imaginativa humana que tanto se manifiesta en el siglo de oro español como en el momento actual.

Las migraciones de la atención del antropólogo aragonés serpentean en tiempos y lugares, se fija con detalle en la producción creativa de la Granada de la Alhambra para saltar vertiginosamente hasta la expresión creativa de la novela realista del siglo XIX y recorrer lentamente los jardines literarios de los autores de la generación del 98. ¿Cómo es posible analizar la creatividad poética desde la antropología? ¿cuáles son los canales que conectan?, ¿por qué la poesía y la literatura interesa al pensamiento antropológico del profesor Lisón?

En un sutil análisis de la obra del insigne pensador y precursor de la etnografía como fue el hispanotunecino Ibn Khaldûn se insiste en la circunstancialidad de toda creación artística; es por supuesto el genius loci un elemento destacado de la creatividad humana, pero no es todo, es también el spirit of time lo que fundamenta la producción literaria humana.

...ni siquiera la personal creación poética se produce en el vacío, es posible y razonable buscar y encontrar anclajes prosaicos, conexiones directas reales y paralelos significantes entre el hacer profesional, el vivir cotidiano y el sublime poetizar (Lisón, 2013, 242).

Esta es una característica peculiar de nuestra literatura hispana ya desde los clásicos del siglo de oro hasta los novísimos. Resulta loco y tempo-sensitiva, y 
atractiva, por tanto, para la lente antropológica. El olfato humanista del profesor Lisón percibe sus posibilidades de análisis en las metamorfosis producidas desde la topografía penínsular hasta la topología alegórica. Dos elementos profundos de la naturaleza humana: por una parte, lo terrenal, el modo de vida fáctico del que toda antropología al modo lisoniano ha de partir; y, por otro lado, el impulso creador que se manifiesta como una posibilidad entre varias en función de libertad imaginativa y creativa. Es precisamente este doble proceso el que despierta, siempre bumilis stylus, el interés del antropólogo aragonés homenajeado.

Aún así, como el estilo define al personaje como han señalado ya los clásicos, en el ensayo titulado Creatividad: la máscara de la objetividad y del misterio deja deslizar una expresión alemana muy del gusto del autor para este doble proceso, la transformación de lo dingliche en undingliche inseparable y permanente. (Lison, 2013, 243).

Si en algún momento este paso de lo objetivo a lo subjetivo despierta sobremanera el interés del antropólogo es en la novela realista de nuestro siglo XIX. El modo de describir apasionadamente este mundo objetivo que se esconde en cada una de estas creaciones literarias denota el interés con el que han sido tratadas por el profesor Lisón. La lista es larga y extensa y se extiende del sur al norte peninsular. Cualquier antropólogo interesado, como es el caso, no puede dejar pasar esta oportunidad para acercarse al modo de vida andaluz, al costumbrismo y vida tradicional en textos como Pepita Jiménez o Juanita la Larga. Es claro, por tanto, que la creación poética no se ha producido en el vacío, lo dinglich aparece para ser motivo de observación etnográfica de la mano de la historia en la obra del escritor, diplomático y político Juan Valera. A partir de las tesis estéticas del romanticismo, el escritor cordobés envuelve la trama en un contexto costumbrista que se debate entre la recuperación de un pasado valioso desde el punto de vista etnográfico con un empuje moderno hacia el mundo urbano e industrial que se aviene a un ritmo acelerado. Como el profesor Lisón remarca, un antropólogo interesado no debe dejar pasar este tesoro de la creatividad hispana y espigar en él. Faenas agrícolas, modos de vida rurales, estampas sobre romerías o informaciones sobre fiestas y celebraciones, más que supervivencias son parte de la realidad fáctica de la que parte la hermeneútica antropológica. Juan Valera y Goya están emparentados en esta fase de la creatividad artística con claro valor etnográfico y no escapan al interés del profesor aragonés.

Como hemos dicho la lista es larga, riqueza del tesoro hispánico literario que ofrece también un testimonio indudablemente rico en la obra de José María de Pereda, el novelista de Polanco afín al carlismo. El momento histórico es de una enorme brillantez, resuenan los ecos de Menéndez Pelayo, Gregorio Marañón y el propio Gerardo Diego, compañeros del escritor cántabro. Carmelo Lisón centra su atención en El sabor de la tierruca, así como en Sotileza, obras en las que, de nuevo desde una perspectiva costumbrista, se narran modos de vida peculiares de la montaña y de los pescadores de la costa santanderina, sus tradiciones, folclore y su organización social. Es en la obra de Pereda donde él percibe de un modo claro 
la tensión que le interesa, esta dialéctica provocada por lo fáctico, tradicional, por la fuerza realista que contextualiza los textos y el lirismo creativo que estiliza la vida rural y mitifica el mundo natural.

El siglo XIX literario español presenta un gran número de primeras plumas que ofrecen al lector una rica perspectiva del llamado regionalismo hispano, pues ponen de manifiesto algo que el propio profesor Lisón gustaba de afirmar, como era la fascinación por la diferencia. El siglo puede ser llamado, como acertadamente señala el profesor González Alcantud, el siglo de la filología, mientras que el siglo XX queda señalado como el de la antropología, por eso, la afinidad electiva entre ambas disciplinas es más que pertinente, casi se nos antoja necesario. (González Alcantud, 2006, 5).

En el caso de las novelas de Blasco Ibañez la diferencia resulta ser el contexto levantino de Albufera y de cultura mediterránea que se ofrecen en La Barraca o en Cañas y Barro, o bien, es la curiosidad que despliega entre brumas Emilia Pardo Bazán en los Pazos de Ulloa y la Madre naturaleza. Autores que combinan la creatividad literaria con un afán descriptivo de la sociedad que respiran y que tan bien conocen.

Es recurrente en la obra del profesor Lisón el interés por la literatura observada al modo antropológico. Ya en el año 1995 coordina un volumen dedicado íntegramente a esta relación pionero en nuestro país en el que participan algunos de los más importantes científicos sociales. En este volumen se presentan trabajos que indagan en la relación entre la etnografía y la narrativa, se analiza la literatura popular, las tradiciones narrativas orales, las distintas formas poéticas, así como algunos casos concretos de literaturas mexicanas, africanas y mediterráneas como temáticas más representativas. El volumen concluye con un interesante texto del propio antropólogo aragonés titulado Subjetividad: la máscara de la objetividady del misterio, en el que vuelve a insistir en la importancia que tiene el estudio de la creatividad para entender y comprender la naturaleza humana. La lectura de estos relatos al modo antropológico pone de manifiesto su detallada observación, característica común a la corriente europea costumbrista que apela de forma decidida a lo local, bien sea en el habla, en el comportamiento, en las costumbres o en las voluntades haciendo, como el propio Lisón afirma, la delicia del antropólogo.

Todos ellos y cada uno a su manera enmascaran, colorean, fantasean, todos ellos transcienden la mostrenca realidad que se dramatiza a su vera, alcanzan la metáfora desde la que se deslizan a la simbolización y de ésta a la alegoría para regalarnos una España poética (Lisón, 2013, 244).

Entre tanta excelencia literaria resulta complicado señalar algún tipo de privilegio o de cercanía emocional por parte del profesor Lisón, sin embargo, creemos que se puede hablar de un gusto destacado por la obra, en primer lugar, de Ramón María del Valle Inclán y de Federico García Lorca, para culminar con Cervantes y el Quijote. En Ramón del Valle Inclán se concentra un interés cultural al tiempo que una deuda histórica que el profesor Lisón siempre consideró que 
la antropología española, ya consolidada en los momentos finales del siglo XX, debía a todos los integrantes de la Generación del 98. Esto se pone de manifiesto en numerosos escritos y referencias en la obra del profesor aragonés, pero se explicita de un modo concreto en el número 7 de la Revista de Antropología Social fundada por el propio Lisón en 1991. Este número correspondiente al año 1998 desechó en su consejo de redacción otras temáticas también interesantes para centrarse en el proyecto presentado por Secundino Valladares sobre los autores de la citada generación y sus contribuciones para un estudio de la cultura hispana en general. (Sanmartín, 2002, 243) El mérito literario ya justifica una esmerada atención de esta generación literaria, pero más allá de la florida creatividad, en el número de la revista citada se valora su contribución a un discurso antropológico universal. (RAS, 7, 13) que supone un impulso a una disciplina que convive de manera permanente con el lenguaje y que presenta una fuerte exigencia narrativa.

El año y la efeméride se prestaban al reconocimiento y al análisis de los noventayochistas, como Unamuno, Azorín, Ganivet, Baroja, Machado, Maeztu y, por supuesto Valle Inclán, como así se hizo. En este importante texto reconocidos investigadores y profesores recogen el guante propuesto y analizan con gran detalle las aportaciones que los miembros de esta prolija generación realizaron a la antropología social en clara concordancia con el trabajo realizado por el profesor Lisón. Cualquier ocasión es propicia para recuperar la lectura de este número de la Revista de Antropología Social, desde nuestro punto de vista, no suficientemente valorado. Pues si bien es cierto que la tradición antropológica española tarda en consolidarse, no es menos cierto que la creatividad puesta al servicio de la descripción etnográfica cuenta en nuestra historia con ilustres representantes. Léase de nuevo el texto del profesor Gómez Pellón sobre Unamuno, o bien, recuérdese la figura de Ángel Ganivet y su escritura compulsiva a través de la pluma siempre sugerente y sabia del profesor González Alcantud y complétese esta visión noventayochista con los estudios sobre Azorín del profesor Álvarez Munárriz y con la excelente descripción del modo de vida popular que emana de las Comedias Bárbaras del gallego Valle Inclán llevada a cabo por el profesor Couceiro. El acercamiento a esta literatura con la lente antropológica se completa con los estudios sobre Pio Baroja, Maeztu y Antonio Machado.

Es amplia la temática objeto de interés cultural en muchos de estos escritores. Ahora bien, la tensión que ha interesado tanto al profesor Lisón entre lo fáctico y su deformación impulsada por la creatividad humana en sus variadas formas y posibilidades se manifiesta de un modo brutal en la obra del escritor gallego. En el plano fáctico se encuentra el mundo rural gallego, un contexto vital que el profesor Lisón ha ido conociendo en su peregrinar etnográfico y que ha ido reconociendo en la obra de Valle Inclán. Le otorga una gran valía de observador, al modo antropológico, sutil, yendo más allá de lo aparente y deslizándose hacia ese espacio de trastienda de la cotidianidad donde los antropólogos reconocemos las reglas y las pautas culturales naturalizadas, invisibilizadas para el profano. Ahí, en esa trastienda sitúa el escritor gallego sus personajes, sus afectos, sus 
preocupaciones y sus miedos a través de una poderosa deformación fruto de una imaginaria antropología creadora. La realidad, por tanto, queda reinventada en distorsión como observamos en muchos rituales, mascaradas, tiempos festivos y de inversión en la cultura popular. Objetividad y subjetividad de nuevo en tensión, yendo de la mano en la obra del genial escritor gallego. Al profesor Lisón le interesa especialmente el carácter atemporal de esta realidad fáctica imaginativamente deformada. Es la vida popular que se presenta, y así lo señala textualmente el propio profesor, en su macabra y lírica intemporalidad.

...esto se debe a que el gran maestro gallego describe en y desde su Galicia, impulsos elementales, fuerzas primordiales panhumanas, el irreductible misterio de la vida, navegando, timoneado por la libertad de su imaginación creadora, de la realidad al símbolo, de este al mito y del mito al misterio, máscara última de la que se reviste la subjetividad (Lisón, 2013, 245).

Esta tensión entre lo ancestral y la máscara de la subjetividad que tanto interesa al profesor aragonés es central en muchas de las obras de García Lorca, quien avanza incluso un peldaño más en la libertad creadora. Supone el despegue de la inspiración, ya no hay límites sociales, ni términos, ni categorías solamente admirable libertad. Es un camino recorrido a través de la literatura pero es ejemplo de la naturaleza humana, de lo fáctico a la absoluta libertad que desdibuja la realidad y enmascara, cuando no cercena, su sentido más profundo. Del costumbrismo a Lorca pasando por los noventayochistas. Así ejecuta la imaginación creadora sus obras, así ha sido en el arte, en la música de Stochahausen, en los cuadros de Gauguin, o de Beckmann, en la poesía de Rimbaud o en los poemas de Rilke, pero así ha sido y es también en la cultura popular, en los rituales y mitologías ancestrales, algo incluso que transciende, algo misterioso.

Objetividad y subjetividad forman parte de la creatividad humana. Son dos caras de una misma moneda, si bien alguno de los elementos puede desbordarse y es cuando surge en misterio.

La subjetividad puede expresarse en producciones tangibles, temporales que son su otra dimensión. Pero hay algo además, en la ontología de la subjetividad, intrínseco e inalcanzable en su esencia y totalidad. En la creación artística hay una quidditas misteriosa que ninguna sutileza de análisis ni ninguna profundidad analógica puede revelar (Lisón, 2013, 248).

\section{MARGINACIÓN Y LIMINALIDAD. LA FASCINACIÓN ANTROPOLÓGICA POR EL QUIJOTE}

De Góngora a Garcilaso, pasando por el gran Valle Inclán hasta García Lorca, todos merecen del profesor Lisón una consideración. Ahora bien, la admiración es mayor si cabe con Cervantes, que incluso le ofrece un aparte, una reflexión antropológica pausada, una atención destacada. Al caballero de la triste figura dedica el antropólogo aragonés dos ensayos. El primero de ellos publicado con motivo del 
IV Centenario de El Quijote en el año 2006, y el segundo, el mismo año publicado en la revista Anales en su número 83.

En su primer trabajo titulado Marginación y Liminalidad en el Quijote, se ensalza la actitud etnográfica que demuestra el propio Don Quijote y que aparece en el texto de un modo sutilmente expresada. En cambio, en el segundo texto la atención se coloca sobre la condición mítica de la obra y su papel en la cultura hispánica. Las miradas son complementarias y, tanto en una como en la otra se percibe el entusiasmo y la estima que transmite su significación antropológica.

Esta actitud quijotesca, etnográfica comienza al salir de camino con la intención de ver mundo. En el texto de Cervantes se enfatiza la salida del caballero andante al campo, una salida inicialmente errática, pero con el objetivo claro de cumplir con un ideal épico. Algo debe de ocurrir, alguna aventura ha de presentarse en este deambular caballeresco. Esta salida trae al recuerdo las palabras de un ilustre etnógrafo, maestro de maestros, quien al estar rodeado de indígenas americanos y ser preguntado en su trabajo de campo acerca de qué quería y qué hacía allí, siempre respondía: simplemente estoy aquí y quiero solamente platicar, algo interesante resultará de la plática. Lo mismo ocurre con estos primeros pasos de Don Quijote, como los primeros momentos de un trabajo de campo: algo interesante resultará de este deambular.

Son numerosas, casi infinitas las lecturas del Quijote realizadas por especialistas de varias disciplinas, si bien, nadie se había acercado a su figura como si fuera un etnógrafo en busca de aventura por los caminos del siglo de oro español. La dinámica antropológica, como la aventura caballeresca exige diálogo indagatorio, curiosidad, interpelación que el propio Don Quijote va haciendo a cada uno de los personajes que se va encontrando en el camino.

dadme cuenta de quién sois, de dónde venís, adonde vais, qué es lo que en aquellas andas lleváis...

Hombres y mujeres de carne y hueso, de todo pelaje y condición, pero reales que muestran, en sus andanzas y sus maneras, una diversidad tan poliédrica como apasionante. No es de extrañar que el profesor Lisón, con la lente antropológica se encuentre embebido ante esta fluencia de diversidades humanas. Hampones sevillanos, habituales de mesones y vagabundos y delincuentes de poca monta en la España del siglo XVI que tan bien conoce y describe Cervantes entre otros caracteres que van apareciendo a lo largo de la obra entre hazaña y hazaña, entre desventura y desventura. Esta descripción ampulosa y densa de la alteridad en la España que también era imperial atrapa al antropólogo aragonés en su particular acercamiento a la obra de Cervantes.

Cervantes fija su retículo en la España soterrada en la que pululan pordioseros, malandrines y fugitivos sin blanco (pág. 251).

Es una mirada desde abajo la mirada cervantina, como lo es la forma de observar antropológica. Una mirada que ve una España como un laberinto de 
razas y culturas, en definitiva, plagada de formas alternativas y diferentes de vivir. Campesinos, conversos, moriscos que se entrelazan en las páginas cervantinas con duques, marqueses, condes y clérigos. Es un mundo social por el que transitan los antropólogos y la antropología, por eso sorprende que la disciplina no se haya acercado antes al mundo cervantino con estos ojos etnográficos. Es esta marginalidad la que ofrece al caballero de la triste figura sus aventuras. En un ejercicio clasificatorio el profesor Lisón enumera estas figuras marginales que van apareciendo a lo largo de la obra: negros, esclavos, gitanos, ciegos, mendigos, vagabundos, ladrones, bodegueros, molineros, pescadores, porqueros, pajes, barrenderos y criados, mozas, pícaros, peregrinos, bulderos, sacristanes, titiriteros, salteadores y ermitaños, entre otros. Masa entrelazada, abigarrada y numerosa, pero que conforman pequeñas subculturas particulares que permiten el conocimiento local. Es valor de Cervantes dar voz a la marginalidad a través de los ojos quijotescos. La creatividad se presenta en este caso de dos modos, por un lado, de forma colectiva generada de prácticas culturales diversas en tiempos, espacios, formas, etc. Más luego se presenta también de forma individual, como fuerza creadora propia, cuyo ejemplo lo vemos en casi todas las líneas. Sin embargo, ¿cuánto de real hay en la obra de Cervantes?, ¿cuánta antropología hay en El Quijote?, ¿cuánta antropología hay en algunas obras literarias? A medida que los ojos y la pluma del profesor van avanzando en la lectura del Quijote aparecen las preguntas.

Literatura y antropología han formado tradicionalmente parte del mismo horizonte: cronistas, viajeros, misioneros, aventureros describían con profusión lo que habían visto y oído sin reparar en la formalidad ni objetividad del relato. Lo que era una complementariedad enriquecedora se tornó en relación formal allá por el final del siglo XIX y principios del siglo XX. Por un lado, los antropólogos recién admitidos a regañadientes en el mundo científico positivista se afanaban por alejarse de cualquier sospecha de ficción en sus relatos, y, en cambio, los artistas y literatos sienten una atracción especial por "el primitivismo", objeto de atención y de estudio de la antropología. Picasso experimenta su transformación artística en los salones del museo etnográfico del hombre en Trocadero, se interesa por las máscaras africanas que luego pinta en Las Señoritas de Avignon, o Víctor Segalen, al regreso de su viaje por Oceanía se plantea su proyecto del Ensayo sobre el exotismo. (Orrego y Serje, 2012). Pero es, a partir de los años 80 cuando más o menos se firma un tratado de no agresión ante la crisis de representatividad que ambas disciplinas sufren juntas (Godelier, 2016) y se abre un periodo creativo de apertura de la antropología hacia otras formas de representar la realidad que se acercan a la literatura, así como también se asume que hay mucha antropología que descubrir en las obras literarias, siembre y cuando se puedan observar con la sensibilidad cultural. Para ello no es posible una simple lectura, sino que se necesita un adiestramiento lento y concienzudo adquirido a través de un dilatado trabajo de campo como el que presenta el profesor Lisón y que le permite acercarse al Quijote destacando su condición de mito. "¿Qué espacio queda para un ensayo de un inexperto en crítica literaria?», se pregunta el profesor abrumado, 
como cualquiera ante la abundancia de obras sobre el clásico español. A pesar de esta ingente cantidad de comentarios, la obra se encuentra inacabada y resulta su interpretación abierta, más aún tratándose de una obra, como el propio Lisón enfatiza, rica en motivos populares, compuesta por deformaciones de la realidad que pueden ser corregidas o entendidas, con ambigüedades y vaguedades que se suceden y que invitan a la interpretación, así como la sucesión de rasgos y prácticas del carácter cotidiano que invitan a un antropólogo a un análisis, afortunadamente alejado de la crítica literaria. Pues, como toda obra literaria, aparte de todo lo demás es a su vez una obra de creación cultural abierta a ojos extraños. El profesor aragonés pone el acento inicialmente en la insistencia de la pregunta del Caballero de la Mancha en su trasiego. Ante unos carreteros, pregunta. Ante unos cómicos, pregunta. Ante los encamisados nocturnos, pregunta. Ante los galeotes, pregunta. No hay otro modo de conocer ese mundo en el que viven y conviven hombres y mujeres modelados culturalmente que a través de la fina observación primero y la pregunta después. Los ojos del profesor Lisón enfocan aspectos desapercibidos en la obra literaria para otros especialistas, pero no para un antropólogo experimentado y curtido en mil batallas etnográficas. El preguntar es nuestra razón de ser, así como el saber escuchar. La buena etnografía requiere de un feliz encuentro, como el propuesto en la obra cervantina. En ella se unen en feliz armonía una sociedad que encuentra un narrador y un narrador que encuentra su sociedad. Pues etnógrafo y sociedad estudiada a veces se dan la mano, se encuentran y se complementan mutuamente como ocurre en la obra etnográfica del profesor aragonés y sus trabajos sobre Galicia. La sociedad estaba esperando su narrador etnográfico, como la sociedad del siglo de oro estaba esperando a su Cervantes.

También tengo por cierto que tanto la imaginación como la liminalidad que rezuma la obra ofrecen un contrapunto objetivo e histórico, referencial y realista al argumento formal (Lisón, 2013, 251).

Esta sociedad que espera narrador no es la España Imperial, sino una España rural de una fantástica diversidad, pueblos distintos, valles con modo de vida propio, conversos y moriscos que se mezclan con personajes de mal vivir, fugitivos y comediantes que conforman conjunto de humanidad en la marginalidad y liminalidad. Habitar los márgenes, visibilizarlos, dotarlos de sentido, convivir en ellos ha sido y es en muchos casos tarea antropológica desde el desembarco de Malinowski en las Trobiand. En estos márgenes Cervantes se mueve con soltura y brillantez, de su pluma sale una letanía de personajes del menospreciado mundo rural, decaído y vilipendiado que interesa al etnógrafo Lisón y que Cervantes convierte en el foco de su atención, en el contexto privilegiado de la locura literaria, en el centro de su escritura.

Merece la pena, por tanto, el acercamiento antropológico a la gran obra cervantina. Los personajes que van apareciendo en el texto van conformando un tejido interesante de relaciones social, al gusto de la mirada etnológica. Miembros de la cultura dominante que interaccionan con marginados, con miembros de 
pequeñas subculturas dotadas de identidad y significación propia creando una red multicultural fecunda en códigos diferentes, reciprocidades y sentimientos diversos de pertenencia. En este mundo el profesor Lisón se siente como en casa, se muestra interesado en la búsqueda de los rasgos icónicos de cada subcultura, en la determinación de los pattern culturales, que presenta la obra cervantina. La categorización lingüística es uno de los tesoros que presenta la obra: bulderos, ermitaños, pícaros, venteros, rateros, mozos de mulas, holgazanes, cabreros entre otros, son las subculturas que van apareciendo entre las andanzas del caballero de la triste figura. Hay, por tanto, una mirada hacia dentro, hacia los modos de pertenencia de sus miembros a estos grupos marginados, pero al mismo tiempo, merece la pena realizar una mirada externa, pues son la expresión de la alteridad. El Quijote ofrece al análisis antropológico un juego complejo de gramáticas de la alteridad aún sin explorar conformada por un conjunto heterogéneo y poliédrico de personajes que se van sucediendo en la trama. (Bauman and Gingrich, 2004; Hall and Du Gay, 2011) Esta es sin duda una temática interesante por explorar, el juego de identidades y de otredades en plena interacción tal y como aparece en el texto cervantino, pero el profesor Lisón centra su atención además en el carácter liminal de la propia figura de D. Quijote como un personaje poseedor de identidades múltiples que se van manifestando a lo largo del escrito. Es racional e irracional, individual y social, es hostil al sistema pero al mismo tiempo utópico, injusto y luchador por la justicia, un ser bifronte, pero sobre todo un ser liminoide. En este rasgo en concreto es donde, según el profesor aragonés, radica su centralidad, pues el liminoide es revolucionario y agente, por tanto, de cambio social. Estos personajes que aparecen en la literatura, forman parte también de la vida real, se encuentran en los trabajos de campo, forman parte del espectro humano, son, en definitiva, como el profesor menciona, los liminoides antropológicos que ocupan una misteriosa región ontológica ocupada por chamanes, excéntricos, brujas, visionarios, locos, genios y artistas muchas veces invisibilizados.

Este mi amo, por mil señales, he visto que es un loco de atar, y aún también yo no le quedo a la zaga, pues soy más mentecato que él, pues le sigo y le sirvo, si es verdadero el refrán que dice: dime con quien andas, decirte he de quién eres (Cervantes, II,10).

Es tarea de la antropología reunir formas de vida diversas para que nada de la condición humana pueda quedarse en el olvido, una condición humana que se desparrama en el personaje de Don Quijote. En la obra encontramos densas descripciones etnográficas como la que nos ofrece en II, 20 sobre la boda campestre. En este caso, la ficción tiende a desaparecer en pos de un realismo casi documental, se describe como un naturalista, se cuenta como un matemático y se presentan los elementos que concurren como un documentalista. La obra se sustenta sobre un manto de realidades sociales y culturales que interesan especialmente al profesor Lisón, pues anticipan el principio de la realidad fáctica y de la investigación inductiva que vemos en toda su obra. Las propias palabras del gran antropólogo aragonés lo describen de un modo inmejorable: 
Al reportar actuaciones reales hace entrar la historicidad en la escena; integra rasgos realistas y verdaderos de una época y un aspecto del mundo bandoleril en un episodio deíctico con carga alegórica pero con peso real que dramatiza códigos, normas y valores pero en discriminadora bivariedad conflictiva, conjuntando la convivencia en solidaridad con la dura violencia real (Lisón, 2013, 259).

Y de esta manera la historia fáctica se abre camino entre tantas aventuras y desventuras del caballero andante descrita con la precisión conceptual del concienzudo etnógrafo. No son solamente el conjunto de términos sino son también lugares que conforman una extensa topografía por la que transita el antihéroe y los personajes que van apareciendo a lo largo de su deambular. Ahora bien, no podemos ir más allá en este acercamiento bumilis stylus al texto de Cervantes. Cabe, sin duda, esta afinidad antropológica, estas sugerencias documentales, pero a pesar de todo sobresale la literatura y su capacidad para superar los cronotopos y alcanzar lo intemporal.

El hidalgo Don Quijote de la Mancha es por derecho propio manchego, pero vive en el empíreo universo del mito (Lisón, 2013, 262).

\section{El QujoTe COMO MiTO}

En el año 2006 y dedicado al antropólogo Luis Álvarez Munárriz escribe Carmelo Lisón un texto breve sobre la obra de Cervantes titulado Dimensiones mitológicas de El Quijote. Junto con el texto presentado anteriormente completa la escritura que sobre el Caballero de La Mancha realizó el investigador aragonés con motivo del centenario de la obra culmen de la literatura española. Como todos los textos en los que se ocupa bumilis stylus de obras literarias, sugiere más que describe y estimula la capacidad interpretativa del lector. En esta reflexión se muestra el profesor Lisón como un escritor con un excelente dominio del lenguaje, afanado en la precisión conceptual aún a sabiendas de forzar semánticas o apoyarse en otras lenguas: serio ludere, modus operandi, mundus inversus, imposibilia, in modo recto, Weltanschaung, charme, the quest, alter ego, auctoritas, potestas, pathos, patterns, son algunos de los términos que de un modo preciso aparecen en el texto y que denotan el afán por una escritura culta y cuidada.

El acercamiento al texto del Quijote se realiza desde su condición ya mítica adquirida con el tiempo. Pertenece así al reducido grupo de obras selectas de la creatividad humana, a las grandes referencias de la humanidad, a los mitos de nuestro tiempo, a la Trinidad creadora como lo expresa el propio Lisón al referirse a Dante, Shakespeare y Cervantes. Ciertamente es abrumador el número de intérpretes y exégetas del texto cervantino, sin embargo, aún queda espacio para una interpretación más, para una mirada nueva que complete a las ya existentes, para que un antropólogo versado en el estudio de la mitología humana lleve a cabo una lectura hermeneútica del mismo que permita abrir nuevos «espacios de 
posibilidad interpretativa». Esta posición sobre la obra cervantina se sitúa en la línea hermenéutica de las prácticas culturales que ha conformado la obra del antropólogo aragonés. Las prácticas y creaciones culturales, el Quijote desde luego que lo es, precisan de una recreación continua pues solamente de este modo reluce su condición de obra genial, irrepetible.

El primer aspecto destacado del texto quijotesco tiene que ver con la urdimbre con la que Cervantes construye su texto. Una trama principal, un patrón que a su vez se ve coloreado, contrastado, conformado con variadas subtramas que, a modo de capítulos, dejan fluir a la trama principal. Así el deambular quijotesco se completa con motivos que hunden sus raíces en la cultura popular y que, por lo tanto, remite a un universal repositorio común que podemos encontrar en el folclore, no solo español, sino europeo. Este aspecto debería estimular sin demora el acercamiento antropológico al texto.

El segundo aspecto a destacar en su acercamiento cervantino se refiere a la condición lúdica del texto. El Quijote fue escrito para hacer reír, sin embargo, el texto alcanza un sentido más allá de la mera hilaridad. A juicio del profesor Lisón, supone un ejercicio genial de ironía con la que describir la verdadera condición humana. La ironía no es una sensación, ni un estado de ánimo, es un modo de acercamiento a la realidad opaca, un modo de conocer.

La ironía cervantina nos ofrece un cierto modo de conocimiento que ni es del todo empírico ni es del todo lógico pero que explora porciones intuitivas de ambos discursos para acercarnos, aunque sea con timidez, a nuestras paradojas existenciales (Lisón, 2013, 275).

En la diferencia entre lo lúdico, sin más afán que divertir, y lo irónico, que despierta un interés epistemológico, radica la condición mítica del texto cervantino. Pues en lo concreto, lo cotidiano, lo habitual que va apareciendo en las aventuras de cada capítulo se esconden aspectos esenciales de la naturaleza humana descritas incluso al modo estructuralista: riqueza-pobreza, legalidadinjusticia, inclusión-exclusión, alma-cuerpo, prudencia-impulso, etc. En estas tensiones sitúa Cervantes a sus personajes, para convertir el caso particular en un patrón universal simbólico, en un acontecer de la naturaleza humana que se manifiesta en estos estadios intermedios de duda, de verdades a medias, de ambigüedades, de indecisiones al modo de Buridán. Estos personajes bifrontes cuestionan certezas asentadas en el juicio precipitado, como es la de considerar única y rígida nuestra identidad humana. El texto cervantino nos enfrenta directamente con acciones y valoraciones que nos obligan a repensar el quehacer humano de forma poliédrica alejado de maniqueísmos y bajo una perspectiva de incertidumbre y de ambigüedad moral. De un modo magistral lo expone el profesor Lisón con estas palabras cuando señala que "la síntesis armónica no es posible para Cervantes".

La insistencia en que la condición humana es plurivalente, ambigua e incierta abre paso a la hermenéutica como modo de análisis de esta realidad que 
admite variedad de descripciones. El juego que nos ofrece Cervantes de presentar unos hechos de un modo, pero al mismo tiempo de otro, e incluso de otro es un ejemplo que le sirve al profesor Lisón para recordarnos la enorme dificultad que tendremos, como antropólogos, cuando nuestra labor consista en descifrar significados, sentidos, signos, símbolos, creencias, deseos e intenciones. En este caso conviene huir de las certezas pues la lógica cultural es dubitativa. Ahora bien, si no hay certezas, ¿qué nos queda? Esta es una idea central en la reflexión lisoniana. Los personajes del Quijote, la mayor parte de ellos procedentes de los márgenes sociales nos dan cuenta de la esencia humana, pues sus acciones nunca están dominadas por la claridad y distinción, al modo cartesiano. En ellas reina la duda y lo incierto por eso están necesitadas de interpretación.

El análisis del profesor Lisón centra su atención a partir de este momento en la condición del caballero andante como héroe cultural. Considera, por tanto, que forma parte de una tradición creativa humana formada por personajes que dejan atrás todo lo que tienen y se adentran en un proceso de indagación sin fin. Son numerosas las referencias en el imaginario humano de estos mitos llamados de búsqueda. La infancia de estos personajes, como la del propio D. Quijote quedan eclipsadas, nada sabemos de ella solamente conocemos rasgos leves de su personalidad y de su carácter marcado por el idealismo, y la excepcionalidad. Sin embargo, la expresión del mito ya es prolija en descripciones a partir de la edad adulta y, sobre todo, después de la inversión de su personalidad. Es común en esta mitología heroica el paso iniciático a través de un ritual que convierte a un personaje común en un alter ego. Es conocido el pasaje en el cual el personaje cervantino pasa la noche entera velando sus armas, lo que le convierte en miembro de la Orden, y defensor por tanto de marginados, y agente del orden social. Sale de su condición de normalidad para adentrarse en un camino de excepcionalidad en el modo de enfrentarse a los distintos sucesos que acontecen. Una vez que asume su papel de héroe, aunque sea interpretado irónicamente, ya trasciende lo cotidiano para ser testigo de aporías de la existencia cultural. Al hablar de altas doncellas, malandrines, barberos, curas, cabreros, pastoras, y otros muchos personajes va más allá de sus vidas concretas y representa lo que de universal hay en ellos. En esto radica su condición de mito, ya que los personajes se convierten en modelos que sienten, sufren y padecen del mismo modo como se hace en todas las culturas. La obra literaria de Cervantes permite al profesor Lisón indagar en la naturaleza de lo mítico de una manera magistral. Desde nuestro punto de vista estos pasajes son los más brillantes del análisis del Quijote. El mito, por tanto, contiene una lógica interna escondida en su manto polifónico, y condensa un sinfín de impulsos y estados humanos permanentes, formas distintas de ver lo humano, lo demasiado humano más allá de circunstancias, de lugares y de tiempos. En el mito se ve lo humano desde otra perspectiva por eso se encuentra abierto a la poética, es fruto de la extensa creatividad humana y requiere para su interpretación de una fina hermenéutica. 
El mito conforma el espacio en el que la libertad de acción y la imaginación no tienen límite, espacio que tiene su hontanar en la creatividad que fluye en la frontera de la liminalidad (Lisón, 2013, 277).

El Quijote, por tanto, marginalidad, liminalidad y mito. Son los tres pilares en los que se concentra la mirada del profesor Lisón sobre este texto clásico. Fiel testigo de la cultura popular, ejemplo de la posición liminal y su fecunda creatividad y portador de universales humanos.

\section{CODA Finalis. ANTROPOlOGía CREATIVA}

En la literatura hay hombres y mujeres que hacen cosas, que dicen y que piensan, que entran en diálogo con otros, que sufren, que ríen y que viven sus vidas al límite de lo humano como en la vida misma. La diferencia con el trabajo de campo resulta evidente, pero permite, en medio de la ficción, la realización de una hermeneútica antropológica bumilis stylus. El acento puesto en la creatividad humana, lejos de desviarse del trabajo de un antropólogo más bien se acerca a él, pues hay una buena dosis de creatividad en la producción etnográfica como bien ha sabido resaltar el profesor Sanmartín.

Reflexionar sobre la creatividad ha sido pues una necesidad impuesta por la propia etnografía. Sólo después o en medio aún de esa experiencia, he empezado a comprender que la diferencia entre un caso y otro no se debía tanto a una manera diferente de hacer antropología, sino fruto de la misma disparidad de lo estudiado (Lisón, 1998, 185).

Este tránsito por lugares poco frecuentados por los antropólogos bien merecía un epígono que siguiese ese fino pero robusto hilo rojo con la intención de conformar algo así como una antropología creativa; un trabajo que fuera más allá de lo textual y que se encontrara cara a cara con los artistas en un intento de consolidar las afinidades electivas abiertas por el profesor Lisón. En el texto titulado Antropología: horizontes teóricos, el profesor Sanmartín aborda este tema en clara consonancia con lo ya presente en la obra de nuestro antropólogo aragonés. La creación, por tanto, es un elemento afín a las epistemologías que priman tanto o más las preguntas que las respuestas, y que se ocupan en buena medida, más del oír, escuchar y ver que del contar y medir.

Este sostén o alargamiento de la escucha y vivencia de la pregunta, convirtiendo al observador en sujeto paciente de una necesidad cuyo desarrollo conducirá a la creación de nuevos significados, constituye un estilo o una manera de trabajar que, de un modo básico y global, comparten el arte y la antropología (Lisón, 1998, 189).

Ejemplo de tesón y de creatividad es la obra que nos ha legado el profesor Lisón. Su lectura y el estudio descansado de la misma es el mejor de los homenajes que los que tuvimos la suerte de conocerlo en vida y recibir su magisterio 
podríamos hacerle. Su legado es una invitación a continuar con las preguntas antropológicas, las tan queridas Seinsfrage a las que permanentemente alude el profesor aragonés, más si cabe, en un mundo en el que la revitalización de identidades monolíticas y las religiones resultan cada vez más excluyentes. Las palabras finales de D. Quijote antes de la realización de su testamento resultan apropiadas en este momento.

Las misericordias, respondió D. Quijote, sobrina, son las que en este instante ha usado Dios conmigo, a quien como dije, no las impiden mis pecados. Yo tengo juicio ya, libre y claro, sin las sombras caliginosas de la ignorancia, que sobre él me pusieron mi amarga y continua leyenda de los detestables libros de las caballerías. Yo conozco sus disparates y sus embelecos, y no me pesa sino que este desengaño ha llegado tan tarde, que no me deja tiempo para hacer alguna recompensa, leyendo otros que sean luz del alma (Cervantes, segunda parte, LXXXIV).

Acerquémonos a la obra de Carmelo Lisón antes de que sea, como preludia Cervantes, demasiado tarde. Dialoguemos con ella para obtener sobre estas preguntas esenciales de vida un juicio libre y claro, combatamos los idola fori, sus disparates y sus embelecos para obtener la recompensa que D. Quijote no pudo tener, la tan ansiada luz del alma.

Descanse en paz.

\section{REFERENCIAS BIBLIOGRÁFICAS}

Aristóteles. (2014). Ética a Nicómaco. Madrid: Alianza Editorial.

Bauman, G.; Gingrich, A. (2004). Grammars of identity/alterity. A structural approach. Oxford: Berghahn Books.

Díaz Viana, L. (2005). Cifrando y descifrando el mundo: la etnoliteratura, una Antropología desde lo literario. RDTP, 60, pp. 7-41.

Fuente Lombo, M. (1994). Etnoliteratura: un nuevo método de análisis en antropología. Córdoba: Universidad de Córdoba.

Godelier, M. (2016). En el mundo de hoy, la antropología es más importante que nunca. AIBR, Revista de Antropología Iberoamericana, pp. 59-77.

González Alcantud, J. A. (2006). La fábrica de los estereotipos. Madrid: Adaba editores.

Hall, S.; Du Gay, P. (2011). Cuestiones de identidad cultural. Buenos aires: Amorrortu

Lisón, C. (1990). Demonios y exorcismos en los siglos de oro. La España mental. Volumen I y II. Madrid: Akal.

Lisón, C. (1996). Temas de antropología aragonesa. Antropología y antropólogos ante el milenio, pp. 32-54.

Lisón, C. (1998). Antropología: horizontes teóricos. Granada: Comares.

Lisón, C. (2008). Dimensiones mito-lógicas del Quijote. En C. Lisón (ed.), Antropología: Horizontes míticos (pp. 281-297). Zaragoza: Prensas Universitarias de Zaragoza-Eds. U. de Granada.

Lisón, C. (2013). Antropología: estilos de pensamiento e interpretación. Barcelona: Anthropos Editorial. 
Orrego, J. C.; Serje, M. (2012). Antropología y literatura: travesías y confluencias. Antipodas. Revista de Antropología y Arqueología.

Sanmartín, R. (2002). Una historia para la creación antropológica contemporánea. La Revista de Antropología social. Revista de Dialectología y Tradiciones populares. Junio.

Sanmartín, R. (2020). Carmelo Lisón Tolosana. Una vocación antropológica. Revista de antropología social, 29(2), pp. 103-113.

Sunstein, C. S. (2006). Infotopia. How many minds produce knowledge. Oxford: Oxford University Press.

Tapscott, D.; Willians, A. D. (2006). Wikinomics: How mass collaboration changes everything. New York: Portfolio. 
